\title{
Impact of Online Prescription Management Systems on Biologic Treatment Initiation
}

\author{
Jason E. Hawkes · Manish Mittal · Matthew Davis · Diana Brixner
}

Received: April 8, 2019 / Published online: June 5, 2019

(C) The Author(s) 2019

\section{ABSTRACT}

Introduction: Pharmaceutical firms have begun offering online prescription management systems to facilitate prescription processing. This study evaluated the impact of the HUMIRA Complete Pro (HCPro) online prescription management system on the rate of abandonment and the time to first fill for patients prescribed adalimumab (ADA). A retrospective cohort analysis of patients initiating ADA treatment with or without use of the HCPro online prescription processing system was used to evaluate the impact of HCPro on treatment initiation outcomes.

Methods: Patient-level data for patients with an ADA prescription processed through HCPro

Enhanced Digital Features To view enhanced digital features for this article go to https://doi.org/10.6084/ m9.figshare.8138834.

J. E. Hawkes ( $\square)$

Laboratory for Investigative Dermatology,

Rockefeller University, New York, NY, USA

e-mail: jhawkes@rockefeller.edu

M. Mittal

AbbVie Inc., North Chicago, IL, USA

M. Davis

Medicus Economics, LLC, Milton, MA, USA

D. Brixner

University of Utah College of Pharmacy, Salt Lake

City, UT, USA were mapped to Symphony Health claims for patients initiating ADA between January 2012 and January 2015. The sample included patients aged $\geq 18$ years with a diagnosis of Crohn's disease, ulcerative colitis, rheumatoid arthritis, psoriasis, psoriatic arthritis, or ankylosing spondylitis who had data available 3 months before and after their first ADA claim (index date). Baseline characteristics, prescription abandonment rate, and time-to-first-prescription fill were compared between patients with a prescription processed through HCPro (HCPro cohort) and those without (non-HCPro cohort). The odds of abandonment were evaluated in the 3 months following the index date using a multivariate logistic regression model.

Results: The study included 24,767 patients (535 HCPro; 24,232 non-HCPro). HCPro patients had a greater frequency of initiation at a specialty pharmacy $(66 \%$ vs. $56 \% ; P<0.001)$ and enrollment in AbbVie's patient support program $(71 \%$ vs. $51 \% ; P<0.001)$ as well as a lower copay for ADA ( $\$ 206$ vs. $\$ 265 ; P=0.011$ ). HCPro patients had a lower abandonment rate $(6.4 \%$ vs. $13.9 \% ; P<0.001)$ and reduced days to prescription fill (7.0 vs. $14.4 ; P<0.001)$. After controlling for baseline characteristics, abandonment odds were $43 \%$ lower for patients using HCPro (odds ratio $=0.57 ; P=0.004$ ).

Conclusion: Initiating ADA treatment with an online prescription management system (HCPro) significantly reduces the odds of abandonment and time to first prescription fill. 
Funding: AbbVie Inc., Chicago, USA.

Keywords: Adalimumab; Abandonment; Biologics; Initiation; Health Economics and Outcomes Research; Online portal; Online prescription management

\section{INTRODUCTION}

Prescribing and obtaining biologic therapy can pose significant challenges for healthcare providers and patients. Biologic treatments often require special handling, administration training, and patient education [1]. Further complicating the process, payers have increased the use of cost management measures that can serve as barriers to biologic access [2-8]. Inexperience with specialty pharmacies, benefits verification, prior authorization, and financial assistance programs can cause delays or disruption in treatment [9]. Confusion over additional requirements needed to attain insurance coverage for a biologic prescription or lack of familiarity with financial assistance options may result in abandonment of treatment entirely [6, 10-12]. Pharmaceutical companies, specialty pharmacies, and payers have all begun offering online prescription management systems designed to provide a framework and structure to providers so they can better navigate the prescription process and, ultimately, help patients receive treatment quickly and efficiently. These systems allow several aspects of the prescription process to be completed after an office visit, such as prior authorization, benefits verification, administration training services, and pharmacy assignment. Some systems can also evaluate patients for financial assistance programs and transmit the prescription and eligible discount cards directly to the fulfilling pharmacy.

While prior authorization and formulary design are valuable in ensuring appropriate use of pharmaceuticals from a payer's perspective, verifying coverage and navigating the process impose significant barriers to the ability of patients to initiate their prescribed treatment in a timely manner. Delays, frustrations with the process, and a lack of understanding of copay responsibilities can cause patients to switch therapies or forgo treatment entirely
$[6,7,11,13]$. Abandonment (never picking up a prescription) or primary non-adherence is common for chronic conditions and especially for biologic treatments with high copay amounts [6, 11, 13-15]. Online prescription management systems can automatically verify insurance coverage and expected copay amounts as well as enroll patients in eligible financial assistance programs to ease this burden for patients.

Online systems are designed to streamline the prescription process and help patients initiate treatment. Additionally, some systems allow physicians to submit requests for electronic benefit verification and complete electronic prior authorizations of prescriptions. They can also transmit prescriptions to a patient's chosen pharmacy and provide reminders of prior authorization renewal or refill dates to avoid treatment disruption. While studies have evaluated the impact of patient-centric online prescription management systems for disease management, the effect of physicianfacing systems of prescription processing on patient outcomes has not previously been evaluated, despite their increasing use [16-21]. One example of a multi-functional online prescription management system is HUMIRA Complete Pro (HCPro), which aims to streamline the prescription process for adalimumab, a biologic therapy approved for the treatment of multiple chronic medical conditions [22]. HCPro is available to any physician prescribing adalimumab who has enrolled in the system [22]. The purpose of this longitudinal, retrospective, cohort analysis was to examine the effect of an online prescription management system, HCPro, on adalimumab (ADA) treatment initiation, time to first fill and abandonment rates using real-world data.

\section{METHODS}

\section{Study Design and Data Sources}

A longitudinal, retrospective, cohort study was conducted using patient-level data on the use of HCPro combined with Symphony Health claims data. The patient-level data used in this study 
consisted of prescriptions processed through HCPro and patient support program (PSP) enrollment information provided by AbbVie (AbbVie Inc., Chicago, IL, USA) combined with claims data from Symphony Health (Symphony) (Symphony Health, Phoenix, AZ, USA) using unique, de-identified patient tokens as described below. The HCPro data contain physician requests for benefit verification, prior authorization, financial assistance, or other services with accompanying patient identifiers and submission dates. The PSP data contain dates of enrollment into any specific component of the PSP (e.g., injection training, nurse ambassador support) and were included in the study to control for any independent effect use of these services may have on treatment initiation. The Symphony database collects longitudinal, patient-level information on medical and pharmacy claims from a geographically diverse, large set of electronic claims processors across the USA, including International Classification of Diseases, Ninth Revision (ICD-9), diagnosis codes, dates of service, charge amounts, procedure codes, National Drug Code numbers, and pharmacy types. Importantly, pharmacy data contain claim status, which distinguishes paid, rejected, or reversed claims. A reversal indicates the payer approved the claim, but the patient did not fill the prescription (abandonment). Claims data from the Symphony database were linked to HCPro and PSP data based on deidentified patient tokens. A proprietary Health Insurance Portability and Accountability Act of 1996 (HIPAA)-compliant industry standard encryption engine (Synoma ${ }^{\mathrm{TM}}$, Symphony Health) was used by each data provider to generate unique patient tokens based on identifiable information that was removed from the data provided to researchers, allowing for direct patient linking. Any risk associated with linked data content was evaluated by an external HIPAA statistician who certified patient anonymity of the resulting files. As de-identification was conducted prior to providing data to researchers, and no identifiable protected health information was included in the data used, this study was determined to be exempt from the Institutional Review Board approval process.

\section{Study Population}

Patients aged $\geq 18$ years with a first ADA prescription claim (paid or reversed) between January 2012 and January 2015 were included in this study. Patients with a first ADA claim from a data supplier reporting only paid claims to the Symphony database were excluded, as abandonment cannot be observed for these patients. Patients with Medicare or Medicaid coverage for their first ADA claim were also excluded, as they were prohibited from using manufacturer-provided discount cards, which would affect the patient out-of-pocket cost obligation. The index date was defined using the earliest ADA claim. Each patient was required to have a diagnosis for an autoimmune disease of interest prior to the index date, based on the following ICD-9 diagnosis codes: Crohn's disease (CD) [555.x], ulcerative colitis (UC) [556.x], rheumatoid arthritis (RA) [714, 714.0, 714.8, 714.89, 714.9], psoriasis (Ps) [696, 696.1, 696.8], psoriatic arthritis (PsA) [696.0], and ankylosing spondylitis (AS) [720, 720.0]. Patients were required to have at least one medical claim in the 3 months prior to the index date to assess baseline characteristics and to have pharmacy data coverage for $\geq 3$ months before and after the index date to observe abandonment. The SHS data do not contain an enrollment or eligibility file, so data coverage was determined as an observed claim before and after the study period.

Patients who fulfilled the inclusion criteria were categorized into two cohorts based on whether they had a prescription processed through HCPro (e.g., a request for benefit verification or prior authorization). Patients with a prescription processed through HCPro were assigned to the HCPro cohort, and patients without were assigned to the non-HCPro cohort.

\section{Outcomes}

Two treatment initiation outcomes were evaluated within 3 months following the initial ADA claim: abandonment and time to prescription fill. Abandonment was defined as a reversal of 
the initial ADA claim (indicating the patient did not take possession of the drug) with no paid ADA claim in the following 90 days, consistent with prior studies $[6,12]$. The abandonment rate was calculated as the number of patients who abandoned ADA divided by the total number of patients with a paid or reversed initial claim. Among patients who did not abandon ADA treatment, time to prescription fill was calculated as the days elapsed between the date the prescription was written and when it was filled. Patients with a missing value for the date the prescription was written were excluded from this calculation.

\section{Covariates}

Sociodemographic, clinical, and payer characteristics were evaluated for each cohort. Age, sex, and a geographic-based estimate of household income bracket were assessed using the most recent data available in Symphony prior to the index date. Calendar year, primary payer plan type, expected copay, and use of a specialty pharmacy were evaluated on the index ADA claim. Expected copay amount was calculated as the patient pay amount, net of coupons, or copay assistance programs and was inflated to 2015 USD using the Consumer Price Index for Medical Care. Enrollment in any component of the PSP within 30 days of the index date was measured. Presence of diagnoses for ADA indications, including CD, UC, RA, Ps, PsA, and AS, was assessed on claims prior to the index date. Finally, the Charlson Comorbidity Index was calculated using claims from the 3 months prior to the index date following the enhanced ICD-9 algorithm [23].

\section{Statistical Analyses}

Baseline sociodemographic, clinical, and payer characteristics were summarized using descriptive statistics. Differences in baseline characteristics and outcomes between the HCPro and non-HCPro cohorts were assessed using Wilcoxon rank-sum tests for continuous variables and chi-square tests for categorical variables. A multivariate logistic regression was used to assess the effect of HCPro on the odds of abandonment, with covariates for age, sex, predicted household income, calendar year, plan type, expected copay, specialty pharmacy use, indication, comorbidity index, and PSP enrollment. In all analyses, a two-sided alpha error level of 0.05 was used to indicate statistical significance. All analyses were conducted using SAS 9.4 software (SAS Institute Inc., Cary, NC, USA).

\section{RESULTS}

\section{Sample Selection and Baseline Characteristics}

A total of 24,767 patients (535 in the HCPro cohort and 24,232 in the non-HCPro cohort) were included in the analysis (Fig. 1). The baseline characteristics of the cohorts were largely comparable (Table 1). Both groups had an average age of 48 years, a majority of female patients (about 66\%), and RA as the most common indication (about 60\%). A higher share of the HCPro cohort had a household income between $\$ 75,000$ and $\$ 99,999$ (17.9\% vs. $14.0 \% ; P=0.010$ ), an initial claim at a specialty pharmacy $(65.6 \%$ vs. $56.3 \% ; P<0.001)$, and enrollment in the PSP $(70.7 \%$ vs. $50.8 \%$; $P<0.001)$. A lower share of HCPro patients had a diagnosis of Ps $(20.2 \%$ vs. $24.3 \% ; P=0.029)$. Finally, HCPro patients had a lower copay amount on the initial ADA claim (\$206 vs. $\$ 265 ; P=0.011)$.

\section{Abandonment}

The overall abandonment rate was $13.7 \%$. As shown in Fig. 2, the abandonment rate was 54\% lower for HCPro patients compared with nonHCPro patients $(6.4 \%$ vs. $13.9 \% ; P<0.001)$. After controlling for baseline characteristics, the odds of abandonment were $43 \%$ lower for the HCPro cohort relative to the non-HCPro cohort [odds ratio $(\mathrm{OR})=0.57 ; 95 \%$ confidence interval $\quad(\mathrm{CI})=0.40-0.83 ; \quad P=0.004] \quad$ (Table 2). Patients with RA had the highest abandonment odds (OR 1.27; CI 1.12-1.44; $P<0.001$ ), while those with $\mathrm{CD}$ had the lowest (OR 0.59; CI 


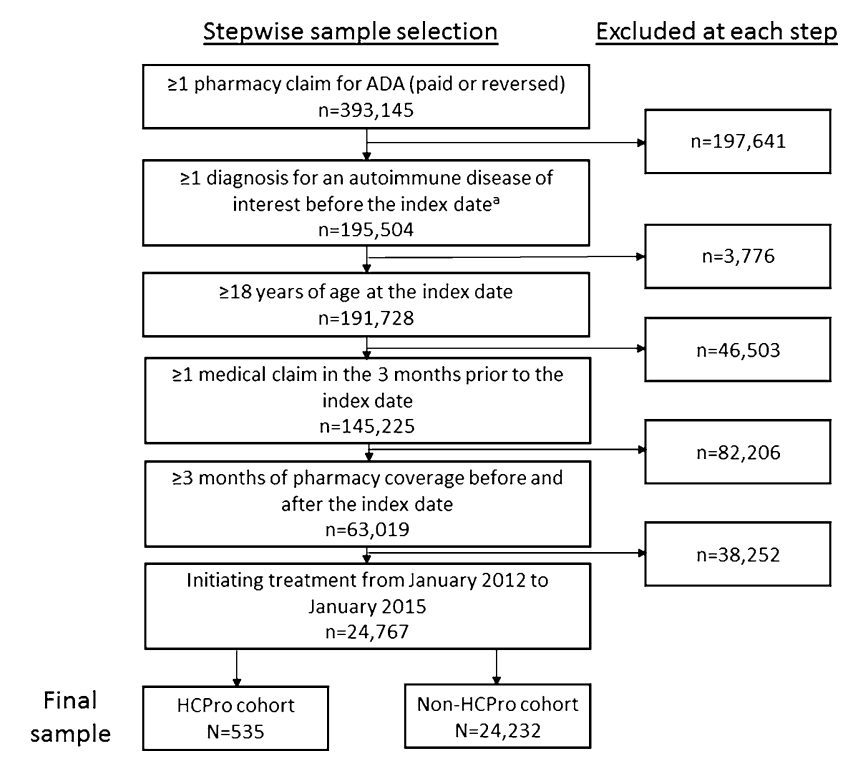

Fig. 1 Sample selection. ${ }^{\text {a }}$ The index date was defined as the earliest ADA claim paid or reversed. $A D A$ adalimumab, $H C P r o$ HUMIRA Complete Pro

0.50-0.70; $P<0.001)$. Odds of abandonment increased monotonically with expected copay level, from OR 2.13 (CI 1.92-2.36; $P<0.001$ ) for copays of $\$ 26-\$ 100$ to OR 10.72 (CI 9.16-12.54; $P<0.001)$ for copays $>\$ 2000$ relative to copays of $\leq \$ 25$.

\section{Time to First Prescription Fill}

Dates when the index prescription was written and first filled were available for $56 \%$ of patients in each cohort. On average, HCPro patients successfully filled their ADA prescription in roughly half the time of non-HCPro patients, with a $51 \%$ reduction in the number of days (7.0 vs. $14.4 ; P<0.001$ ) (Fig. 3a). A higher share of HCPro patients filled their script within 1 week $(66.2 \%$ vs. $55.1 \% ; P<0.001)$ and within 1 month $(97.0 \%$ vs. $87.2 \% ; P<0.001)$ (Fig. $3 b)$.

\section{DISCUSSION}

In summary, we evaluated the impact of a multi-functional online prescription management system (HCPro) on treatment initiation outcomes, prescription abandonment rates, and time to first prescription fill. Use of HCPro was associated with reduced abandonment odds and faster treatment initiation. These findings suggest HCPro may help patients access treatment sooner and more successfully, which could impact other treatment-related clinical benefits. The reduced time to prescription fill suggests that benefit verifications were completed and prior authorizations approved more quickly with HCPro, though this was not explicitly measured or analyzed. These results are potentially of interest to medication prescribers, who may wish to consider using HCPro or other comparable online prescription management systems for rapid prescription processing.

Our results are generally consistent with those of studies examining the impact of initiatives similar to certain features of HCPro. An analysis of electronic prescriptions in the CVS Caremark system found that transmitting electronic prescriptions directly to a pharmacy significantly reduced the likelihood of primary non-adherence to newly prescribed medications by up to $46 \%$ relative to paper prescriptions [24]. After incorporating phoned or faxed prescriptions, electronic prescriptions were still associated with a 10\% increase in first-fill adherence [24]. An evaluation of a centralized, pharmacist-led prior authorization initiative in a university-based medical center showed that 
Table 1 Baseline characteristics

\begin{tabular}{|c|c|c|c|}
\hline Characteristic & $\begin{array}{l}\text { HCPro } \\
N=535\end{array}$ & $\begin{array}{l}\text { Non-HCPro } \\
N=24,232\end{array}$ & $P$ value $^{\mathrm{a}}$ \\
\hline Age (years), mean $\pm S D$ & $48.1 \pm 12.2$ & $48.4 \pm 12.6$ & 0.562 \\
\hline Male, $n(\%)$ & $170(31.8)$ & $8293(34.2)$ & 0.238 \\
\hline \multicolumn{4}{|l|}{ Household income, $n$ (\%) } \\
\hline$\$ 0-\$ 29,999$ & $43(8.0)$ & $1807(7.5)$ & 0.614 \\
\hline$\$ 30,000-\$ 49,999$ & $56(10.5)$ & $2458(10.1)$ & 0.806 \\
\hline$\$ 50,000-\$ 74,999$ & $81(15.1)$ & $3771(15.6)$ & 0.790 \\
\hline$\$ 75,000-\$ 99,999$ & $96(17.9)$ & $3396(14.0)$ & 0.010 \\
\hline$>\$ 100,000$ & $122(22.8)$ & $6384(26.3)$ & 0.066 \\
\hline Unknown & $137(25.6)$ & $6416(26.5)$ & 0.652 \\
\hline Expected patient copay, mean $\pm S D$ & $\$ 206 \pm \$ 678$ & $\$ 265 \pm \$ 1031$ & 0.011 \\
\hline$\$ 0-\$ 25, n(\%)$ & $320(59.8)$ & $13,394(55.3)$ & 0.037 \\
\hline$\$ 26-\$ 100, n(\%)$ & $110(20.6)$ & $6228(25.7)$ & 0.007 \\
\hline$\$ 101-\$ 500, n(\%)$ & $55(10.3)$ & $2244(9.3)$ & 0.421 \\
\hline$\$ 501-\$ 1000, n(\%)$ & $22(4.1)$ & $773(3.2)$ & 0.231 \\
\hline$\$ 1001-\$ 2000, n(\%)$ & $8(1.5)$ & $427(1.8)$ & 0.642 \\
\hline$>\$ 2000, n(\%)$ & $20(3.7)$ & $1166(4.8)$ & 0.250 \\
\hline \multicolumn{4}{|l|}{ Calendar year, $n(\%)$} \\
\hline 2012 & $39(7.3)$ & $8525(35.2)$ & $<0.001$ \\
\hline 2013 & $253(47.3)$ & $8330(34.4)$ & $<0.001$ \\
\hline 2014 & $234(43.7)$ & $6961(28.7)$ & $<0.001$ \\
\hline 2015 & $9(1.7)$ & $416(1.7)$ & 0.952 \\
\hline \multicolumn{4}{|l|}{ Primary plan, $n(\%)$} \\
\hline Commercial & $14(2.6)$ & $765(3.2)$ & 0.479 \\
\hline Employer group & $43(8.0)$ & $2118(8.7)$ & 0.569 \\
\hline Third party administrator & $0(0.0)$ & $67(0.3)$ & 0.223 \\
\hline Pharmacy benefit manager & $139(26.0)$ & $6798(28.1)$ & 0.291 \\
\hline Cash & $70(13.1)$ & $2264(9.3)$ & 0.003 \\
\hline Processors & $8(1.5)$ & $976(4.0)$ & 0.003 \\
\hline Worker's compensation & $0(0.0)$ & $3(0.0)$ & 0.797 \\
\hline Unspecified or missing & $261(48.8)$ & $11,241(46.4)$ & 0.272 \\
\hline
\end{tabular}


Table 1 continued

\begin{tabular}{lllr}
\hline Characteristic & $\begin{array}{l}\text { HCPro } \\
\boldsymbol{N}=\mathbf{5 3 5}\end{array}$ & $\begin{array}{l}\text { Non-HCPro } \\
\boldsymbol{N}=\mathbf{2 4 , 2 3 2}\end{array}$ & $\boldsymbol{P}_{\text {value }}^{\mathbf{a}}$ \\
\hline PSP enrollment, $n(\%)^{\mathrm{b}}$ & $378(70.7)$ & $12,316(50.8)$ & $<0.001$ \\
Initial claim at a specialty pharmacy, $n(\%)^{\mathrm{c}}$ & $351(65.6)$ & $13,638(56.3)$ & $<0.001$ \\
Charlson Comorbidity Index, mean \pm SD & $0.54 \pm 0.8$ & $0.52 \pm 0.8$ & 0.809 \\
Indications, $n$ (\%) & & & \\
Rheumatoid arthritis & $319(59.6)$ & $13,854(57.2)$ & 0.257 \\
Crohn disease & $84(15.7)$ & $3477(14.3)$ & 0.378 \\
Ulcerative colitis & $51(9.5)$ & $1915(7.9)$ & 0.168 \\
Psoriasis & $108(20.2)$ & $5882(24.3)$ & 0.029 \\
Psoriatic arthritis & $97(18.1)$ & $4473(18.5)$ & 0.847 \\
Ankylosing spondylitis & $25(4.7)$ & $1249(5.2)$ & 0.618 \\
\hline
\end{tabular}

HCPro HUMIRA Complete Pro, PSP patient support program, $S D$ standard deviation

${ }^{a}$ Wilcoxon rank-sum tests and chi-square tests were used to compare continuous and categorical variables, respectively

b Defined as enrollment in any PSP component within 30 days of the index date

${ }^{c}$ Defined as a pharmacy type of mail order/specialty

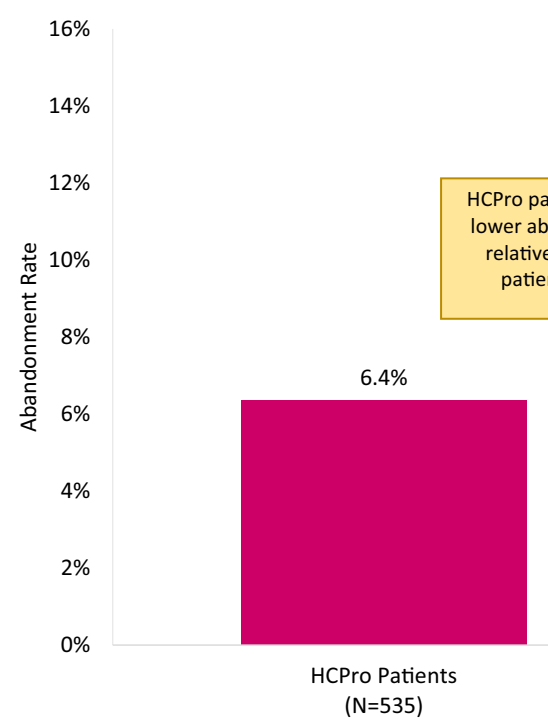

Fig. 2 Prevalence of abandonment by HCPro use. a Abandonment defined as a reversed initial claim for ADA with no paid pharmacy or medical claim for ADA in the subsequent 3 months. b Relative percent change calculated

use of the centralized system improved prescription approval rates and significantly reduced time to approval [25].
$13.9 \%$

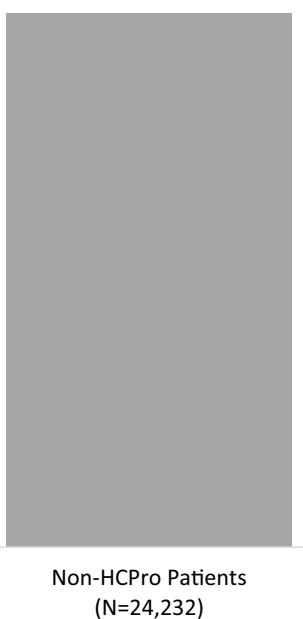

as $($ HCPRO - Non-HCPro)/Non-HCPro $=(6.4-$ $13.9) / 13.9=-54 \%$. c $P$ value calculated using a chisquare two-sample test. $A D A$ adalimumab, HCPro HUMIRA Complete Pro

The reduction in time to first fill found with HCPro use is also consistent with results for other instant approval processes. A study of 
Table 2 Multivariate analysis of the odds of abandonment

\begin{tabular}{|c|c|c|c|}
\hline Characteristic & Odds ratio & $95 \% \mathrm{CI}$ & $P$ value \\
\hline $\mathrm{HCPro}^{\mathrm{a}}$ & 0.57 & {$[0.40,0.83]$} & 0.004 \\
\hline Age (years) & 1.01 & {$[1.01,1.02]$} & $<0.001$ \\
\hline Male & 1.00 & {$[0.91,1.09]$} & 0.953 \\
\hline \multicolumn{4}{|l|}{ Household income } \\
\hline$\$ 0-\$ 29,999$ & Ref & - & - \\
\hline$\$ 30,000-\$ 49,999$ & 0.95 & {$[0.79,1.15]$} & 0.597 \\
\hline$\$ 50,000-\$ 74,999$ & 0.92 & {$[0.77,1.10]$} & 0.320 \\
\hline$\$ 75,000-\$ 74,999$ & 0.93 & {$[0.78,1.11]$} & 0.431 \\
\hline$>\$ 100,000$ & 0.97 & {$[0.82,1.14]$} & 0.671 \\
\hline Unknown & 1.02 & {$[0.87,1.20]$} & 0.810 \\
\hline \multicolumn{4}{|l|}{ Expected patient copay } \\
\hline$\$ 0-\$ 25$ & Ref & - & - \\
\hline$\$ 26-\$ 100$ & 2.13 & {$[1.92,2.36]$} & $<0.001$ \\
\hline$\$ 101-\$ 500$ & 2.80 & {$[2.45,3.19]$} & $<0.001$ \\
\hline$\$ 501-\$ 1000$ & 5.98 & {$[5.01,7.14]$} & $<0.001$ \\
\hline$\$ 1001-\$ 2000$ & 6.33 & {$[5.04,7.96]$} & $<0.001$ \\
\hline$>\$ 2000$ & 10.72 & {$[9.16,12.54]$} & $<0.001$ \\
\hline \multicolumn{4}{|l|}{ Calendar year } \\
\hline 2012 & Ref & - & - \\
\hline 2013 & 1.08 & {$[0.99,1.19]$} & 0.082 \\
\hline 2014 & 0.58 & {$[0.52,0.65]$} & $<0.001$ \\
\hline 2015 & 0.23 & {$[0.13,0.41]$} & $<0.001$ \\
\hline \multicolumn{4}{|l|}{ Primary plan } \\
\hline Commercial & Ref & - & - \\
\hline Employer group & 0.75 & {$[0.57,0.98]$} & 0.036 \\
\hline Third party administrator & 0.43 & {$[0.19,0.98]$} & 0.044 \\
\hline Pharmacy benefit manager & 0.68 & {$[0.53,0.87]$} & 0.002 \\
\hline Cash & 1.19 & {$[0.90,1.59]$} & 0.232 \\
\hline Processors & 0.96 & {$[0.67,1.36]$} & 0.798 \\
\hline Worker's compensation & 0.00 & {$[0.00,99.9]$} & 0.951 \\
\hline Unspecified or missing & 1.29 & {$[1.02,1.63]$} & 0.037 \\
\hline PSP enrollment & 0.23 & {$[0.20,0.25]$} & $<0.001$ \\
\hline
\end{tabular}


Table 2 continued

\begin{tabular}{llll}
\hline Characteristic & Odds ratio & 95\% CI & $P$ value \\
\hline Initial claim at a specialty pharmacy & 1.13 & {$[1.04,1.23]$} & 0.004 \\
Charlson Comorbidity Index & 0.98 & {$[0.93,1.04]$} & 0.568 \\
Indication & & & $<0.001$ \\
Rheumatoid arthritis & 1.27 & {$[1.12,1.44]$} & $<0.001$ \\
Crohn disease & 0.59 & {$[0.50,0.70]$} & 0.248 \\
Ulcerative colitis & 0.90 & {$[0.74,1.08]$} & 0.799 \\
Psoriasis & 1.02 & {$[0.90,1.15]$} & 0.328 \\
Psoriatic arthritis & 0.95 & {$[0.84,1.06]$} & 0.654 \\
Ankylosing spondylitis & 0.96 & {$[0.79,1.16]$} & \\
\hline
\end{tabular}

Estimates were produced using a logistic regression with abandonment of the earliest adalimumab claim as the dependent variable

$A D A$ adalimumab, $C I$ confidence interval, HCPro HUMIRA Complete Pro, PSP patient support program, Ref reference

a Non-HCPro cohort was the reference

proton pump inhibitors showed instant approval of prior authorization requests cut the median gap between prescription fills by half [26]. Furthermore, a study of biologics in psoriasis found increased implementation of prior authorization was correlated with an average increase of $81 \%$ in the time to receive a coverage decision [2]. Finally, a study of an online system for requesting medication refills reported more frequent use was associated with improved adherence for diabetes patients [21]. Further research examining the impact of a multifunctional online prescription management system such as HCPro on longer-term adherence, medical costs, and additional patient- and treatment-related outcomes is warranted.

The HCPro program has many components that may contribute to the observed association with prescription fulfillment, such as assistance with obtaining benefits verification and transmitting prescriptions to a qualifying pharmacy. Our results do not allow us to assess which components of the program had the strongest influence on prescription uptake among patients, but these results provide an early view of the potential impact of multi-functional prescription management systems on treatment initiation outcomes. With broader adoption of online prescription management systems anticipated, future research could provide more insights into the effect of these individual components.

There are several strengths to this study. Our study directly assessed the association between an online prescription management system and patient outcomes using real-world data. The data used include a geographically diverse patient population with a broad range of healthcare plans. The data also contain longitudinal, patient-level information on baseline characteristics, clinical measures, and payer characteristics, which provide for extensive covariates in the multivariate analysis. Finally, this study was conducted outside the controlled environment of a clinical trial that could affect treatment initiation outcomes.

Several limitations should also be noted. First, patients or providers using HCPro may differ systematically from those who do not in characteristics not observable in the data but related to the outcomes assessed (e.g., university-based providers versus those in non-academic practice settings). Second, non-electronic prescriptions abandoned prior to submission to a pharmacy are not observed in the data, which may result in an underestimate of the true 
(a)

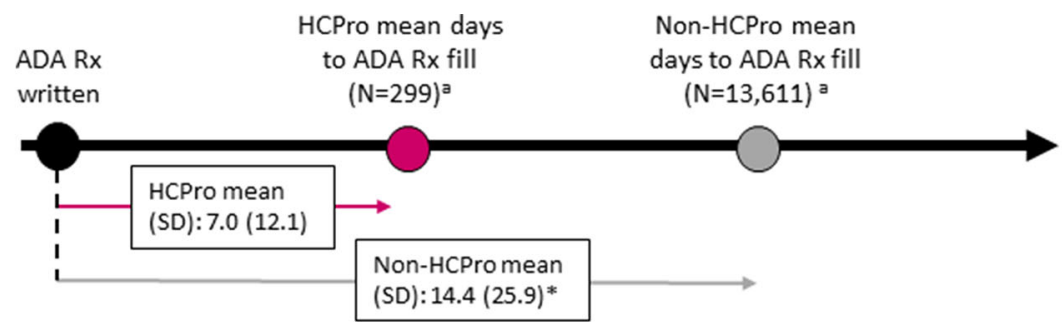

*P-value for difference between mean time to first fill for HCPro and Non-HCPro patients $<0.001^{\mathrm{b}}$

$P<0.001^{\circ}$

(b) 100

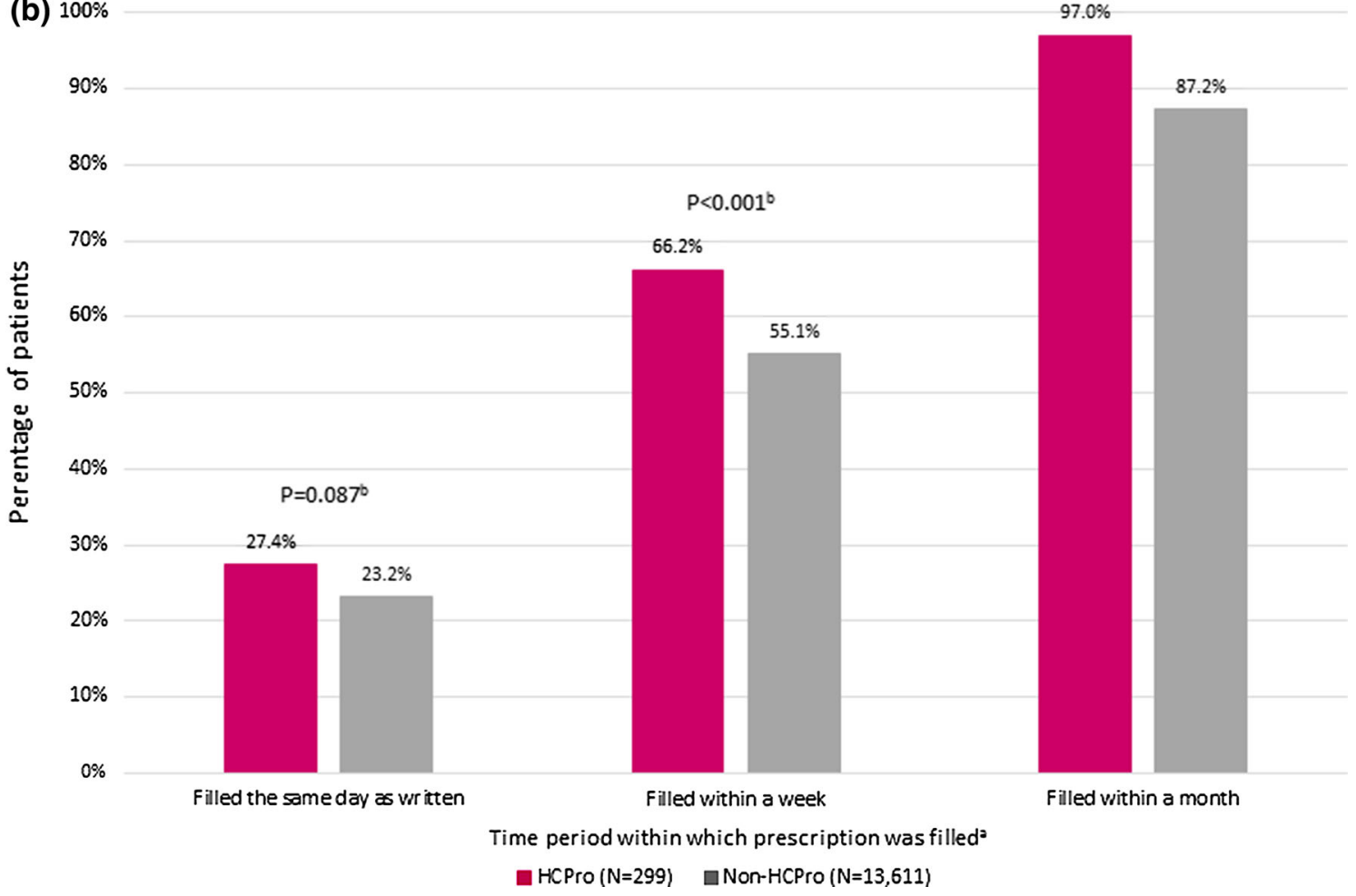

Fig. 3 Analysis of time to first prescription fill. a Mean days to first fill from the date ADA was prescribed. $\mathbf{b}$ The percentage of patients who had filled their first ADA prescription by certain time points. ${ }^{a}$ The date the prescription was written was available for 299 (55.9\%) of HCPro patients and 13,611 (56.2\%) of non-HCPro

abandonment rate for non-HCPro patients and thus a conservative estimate of the benefit of HCPro. Such prescriptions are observable in electronic health records, where a study of RA patients found a primary non-adherence rate of $39 \%$ to biologic treatment initiation [15]. Third, patients with government-provided insurance were excluded because they were prohibited patients $(P=0.897)$. ${ }^{b}$ Wilcoxon rank-sum tests and chisquared tests were used to compare continuous and categorical variables, respectively. $A D A$ adalimumab, HCPro HUMIRA Complete Pro, $S D$ standard deviation, $R x$ prescription

from using copay cards to reduce their out-ofpocket obligation, so results may not be generalizable to Medicare and Medicaid populations. Fourth, the database used in this study did not include an eligibility file, an indicator of whether a given patient was continuously enrolled in the plan, so we cannot verify that we observed all healthcare use by patients included 
in the study. This concern was minimized by requiring continuous data coverage based on observed claims. Lastly, data were not available for online prescription management systems aside from HCPro, so results may not be generalizable to other systems with different capabilities.

This study offers important insights into the possible impacts of digitizing elements of the prior authorization process and other elements of the medication prescription process. Our research uses real-world data to assess the implications of a streamlined, digital system to help physicians and patients navigate prescriptions for a biologic agent. Future research should continue to assess the implications of strategies designed to facilitate prior authorizations and other administrative requirements on patient outcomes.

\section{CONCLUSION}

Overall, this study assessed the impact of having a prescription processed through an online prescription management system (HCPro) on treatment initiation outcomes. Patients with a prescription through HCPro had a significant reduction in abandonment relative to patients who did not. After adjusting for patient and payer characteristics, odds of abandonment remained lower for HCPro patients. HCPro patients also had a significant reduction in time to first fill. These findings suggest online prescription management systems may help patients initiate prescribed treatment sooner and more successfully. Additional studies on the effect of online prescription management systems on longer-term adherence, clinical and resource use outcomes, and the contribution of specific prescription management resources are needed.

\section{ACKNOWLEDGEMENTS}

Funding. Financial support for the study, the article processing charges and open access fee were provided by AbbVie Inc., Chicago, IL,
USA. The study sponsor participated in the design and conduct of the study, interpretation of data, review, and approval of the article. All authors had full access to all of the data in this study and take complete responsibility for the integrity of the data and accuracy of the data analysis.

Medical Writing and Editorial Assistance. Julia Bond, MPH, of Medicus Economics provided medical writing and editing services in the development of this publication. Support for this assistance was funded by AbbVie, Inc.

Authorship. All named authors meet the International Committee of Medical Journal Editors (ICMJE) criteria for authorship for this article, take responsibility for the integrity of the work as a whole, and have given their approval for this version to be published.

Disclosures. Jason E. Hawkes serves as an investigator/consultant for AbbVie Inc., Janssen, Novartis, Pfizer Inc., Regeneron-Sanofi, and VisualDx. Manish Mittal is an employee and stockholder of AbbVie. Matthew Davis is an employee of Medicus Economics, which received payment from AbbVie to participate in this research. Diana Brixner received consulting fees from AbbVie, AstraZeneca, Becton-Dickinson, Millcreek Outcomes Group, Sanofi, UCB Pharma, and Abbott Laboratories.

Compliance with Ethics Guidelines. As deidentification was conducted prior to providing data to researchers, and no identifiable protected health information was included in data used, this study was determined as exempt from the Institutional Review Board approval process.

Data Availability. The datasets generated during and/or analyzed during the current study are not publicly available due to restrictions of the relevant data use agreements, but additional information is available from the corresponding author on reasonable request.

Open Access. This article is distributed under the terms of the Creative Commons 
Attribution-NonCommercial 4.0 International License (http://creativecommons.org/licenses/ by-nc/4.0/), which permits any noncommercial use, distribution, and reproduction in any medium, provided you give appropriate credit to the original author(s) and the source, provide a link to the Creative Commons license, and indicate if changes were made.

\section{REFERENCES}

1. Sullivan SD. The promise of specialty pharmaceuticals: are they worth the price? J Manag Care Pharm. 2008;14(4 Suppl):S3-6.

2. Abdelnabi M, Patel A, Rengifo-Pardo M, Ehrlich A. Insurance coverage of biologics for moderate-tosevere psoriasis: a retrospective, observational 5-year chart review. Am J Clin Dermatol. 2016;17(4):421-4.

3. Willey VJ, Kopenski F, Lawless GD. Beyond the myths: finding benefit design solutions that address the true costs of high healthcare use. Am J Manag C. 2008;14(8 Suppl):S252-63.

4. Zeng F, Park J, Plauschinat CA, Patel BV. Failure to intensify hypertension therapy after rejected aliskiren claims. Clin Ther. 2012;34(5):1122-31.

5. Bergeson JG, Worley K, Louder A, Ward M, Graham J. Retrospective database analysis of the impact of prior authorization for type 2 diabetes medications on health care costs in a Medicare Advantage Prescription Drug Plan population. J Manag Care Pharm. 2013;19(5):374-84.

6. Gleason PP, Starner CI, Gunderson BW, Schafer JA, Sarran HS. Association of prescription abandonment with cost share for high-cost specialty pharmacy medications. J Manag Care Pharm. 2009;15(8):648-58.

7. Curkendall S, Patel V, Gleeson M, Campbell RS, Zagari M, Dubois R. Compliance with biologic therapies for rheumatoid arthritis: do patient outof-pocket payments matter? Arthritis Rheum. 2008;59(10):1519-26.

8. Stern D. Benefit design innovations to manage specialty pharmaceuticals. J Manag Care Pharm. 2008;14(4 Suppl):S12-6.

9. Hansen LB, Fernald D, Araya-Guerra R, Westfall JM, West D, Pace W. Pharmacy clarification of prescriptions ordered in primary care: a report from the Applied Strategies for Improving Patient Safety
(ASIPS) collaborative. J Am Board Fam Med. 2006;19(1):24-30.

10. Desai RJ, Rao JK, Hansen RA, Fang G, Maciejewski ML, Farley JF. Predictors of treatment initiation with tumor necrosis factor-alpha inhibitors in patients with rheumatoid arthritis. J Manag Care Spec Ph. 2014;20(11):1110-20.

11. Hopson S, Saverno K, Liu LZ, et al. Impact of out-ofpocket costs on prescription fills among new initiators of biologic therapies for rheumatoid arthritis. J Manag Care Spec Ph. 2016;22(2):122-30.

12. Starner CI, Alexander GC, Bowen K, Qiu Y, Wickersham PJ, Gleason PP. Specialty drug coupons lower out-of-pocket costs and may improve adherence at the risk of increasing premiums. Health Affair. 2014;33(10):1761-1769.

13. Pasquale MK, Louder AM, Deminski MC, Chambers $\mathrm{RB}$, Haider S. Out-of-pocket costs and prescription reversals with oral linezolid. Am J Manag C. 2013;19(9):734-40.

14. Fischer MA, Stedman MR, Lii J, et al. Primary medication non-adherence: analysis of 195,930 electronic prescriptions. J Gen Intern Med. 2010;25(4):284-90.

15. Harnett J, Wiederkehr D, Gerber R, Gruben D, Bourret J, Koenig A. Primary nonadherence, associated clinical outcomes, and health care resource use among patients with rheumatoid arthritis prescribed treatment with injectable biologic diseasemodifying antirheumatic drugs. J Manag Care Spec Ph. 2016;22(3):209-18.

16. Sarkar U, Lyles CR, Parker MM, et al. Use of the refill function through an online patient portal is associated with improved adherence to statins in an integrated health system. Med Care. 2014;52(3):194-201.

17. Abbott KC, Boocks CE, Sun Z, Boal TR, Poropatich RK. Walter Reed Army Medical Center's internetbased electronic health portal. Mil Med. 2003;168(12):986-91.

18. Epstein JN, Kelleher KJ, Baum R, et al. Impact of a web-portal intervention on community ADHD care and outcomes. Pediatrics. 2016;138(2):e20154240.

19. Kruse CS, Argueta DA, Lopez L, Nair A. Patient and provider attitudes toward the use of patient portals for the management of chronic disease: a systematic review. J Med Internet Res. 2015;17(2):e40.

20. Goldzweig CL, Orshansky G, Paige NM, et al. Electronic patient portals: evidence on health outcomes, satisfaction, efficiency, and attitudes: a systematic review. Ann Intern Med. 2013;159(10):677-87. 
21. Ammenwerth E, Schnell-Inderst P, Hoerbst A. The impact of electronic patient portals on patient care: a systematic review of controlled trials. J Med Internet Res. 2012;14(6):e162.

22. AbbVie. HUMIRA Complete Pro website. https:// www.humirapro.com/humira-complete/physicianresources. Accessed 30 Apr 2019.

23. Quan H, Sundararajan V, Halfon P, et al. Coding algorithms for defining comorbidities in ICD-9-CM and ICD-10 administrative data. Med Care. 2005;1:1130-9.
24. Fischer MA, Choudhry NK, Brill G, et al. Trouble getting started: predictors of primary medication nonadherence. Am J Med. 2011;124(11):1081. e1089-90.

25. Cutler T, She Y, Barca J, et al. Impact of pharmacy intervention on prior authorization success and efficiency at a University Medical Center. J Manag Care Spec Ph. 2016;22(10):1167-71.

26. Wegner SE, Trygstad TK, Dobson LA Jr, Lawrence WW Jr, Steiner BD. A physician-friendly alternative to prior authorization for prescription drugs. Am J Manag C. 2009;15(12):e115-22. 